\title{
Marked alterations in circulating inflammatory cells during cardiomyopathy development in a magnesium-deficient rat model
}

\author{
BY JOSEPH KURANTSIN-MILLS ${ }^{1,2}$, MARIE M. CASSIDY ${ }^{2}$, RICHARD E. STAFFORD ${ }^{3}$ \\ AND WILLIAM B. WEGLICKI ${ }^{3}$ \\ ${ }^{1}$ Division of Hematology and Oncology, Department of Medicine, ${ }^{2}$ Department of Physiology, and \\ ${ }^{3}$ Division of Experimental Medicine, Department of Medicine, The George Washington University \\ Medical Center, Washington, DC 20037, USA
}

(Received 4 December 1996 - Revised 21 April 1997 - Accepted 9 May 1997)

\begin{abstract}
Rodents fed on a Mg-deficient (Mg-D) diet develop cardiomyopathic lesions, as well as other types of cardiovascular dysfunction. In the rat, inflammatory cell infiltration of the myocardium begins to occur by week 1 , and the lesions develop extensively in the third and fourth weeks on the Mg-D diet. Although the aetiologic mechanisms of Mg-D cardiomyopathy are unknown, we have previously reported that once plasma $\mathrm{Mg}$ is markedly reduced, one of the earliest molecular markers of the pathophysiological process is elevation of plasma substance $P$, calcitonin gene-related peptide and prostaglandin $E_{2}$, followed by histamine and the inflammatory cytokines (interleukin-1, interleukin6 , and tumor necrosis factor- $\alpha$ ). In order to evaluate the potential role of specific circulating inflammatory cell subpopulations in the mechanisms underlying pathophysiological changes observed in Mg-deficiency-induced cardiomyopathy, we analysed these cells by flow cytochemistry. Leucocyte subpopulation pools increased progressively in the Mg-D rats. Elevated circulating levels of neutrophils and lymphocytes appeared to contribute to both the acute (week 1-2) and chronic phases (week 3-4) of the inflammatory responses; monocytes, esinophils, basophils and large unstained cells which are lymphoid in stained smears, on the other hand, increased significantly in the third and fourth weeks and thus contributed to the chronic inflammatory phase. Changes in the circulating leucocyte subpopulations paralleled the chronological progression of the cardiomyopathic lesions, particularly in weeks 3 and 4 . Since a pronounced neutrophilia preceded leucocyte infiltration and deposition within the myocardial tissue, modifications of the microvascular barrier may be a prerequisite for cardiomyopathy in this model of neurogenic inflammation.
\end{abstract}

Magnesium: Neutrophilia: Inflammatory cells

There is ample evidence correlating $\mathrm{Mg}$ deficiency and cardiovascular diseases such as coronary artery disease, cardiac arrhythmias, and IHD (Seelig \& Heggtveit, 1974; Altura, 1986; Seelig, 1989). Mg deficiency has also been noted among alcoholics and patients on diuretics (Seelig, 1989). $\mathrm{Mg}$ is an essential element in the regulation of the functional activities of over 300 enzyme systems (Aikawa, 1981). In spite of the importance of $\mathrm{Mg}$ in cellular reactions and the cardiovascular consequences of $\mathrm{Mg}$ deficiency, the pathophysiological mechanisms are still relatively undefined. Mg deficiency reduces rat erythrocyte GSH levels (Mills et al. 1986), presumably due to reduced GSH biosynthesis. Other investigators have reported increased erythrocyte membrane fluidity during $\mathbf{M g}$ deficiency (Tongyai et al. 1989; Freedman et al. 1990b). Furthermore, erythrocytes of Mg-D hamsters are more vulnerable to an applied free-radical stress compared with the cells of $\mathrm{Mg}$ - 
supplemented animals (Freedman et al. 1990b). An increase in platelet and leucocyte abundance has been observed in the Mg-deficient hamster model (Rishi et al. 1990). However, Battifora (1973) did not observe an increase in platelet abundance in rats fed on a Mg-deficient diet, perhaps due to species differences. In a series of studies aimed at defining the mechanisms underlying the cardiomyopathy which results from $\mathrm{Mg}$ deficiency, we have found that antioxidant intervention significantly reduces the number and size of the inflammatory cardiac tissue lesions, suggesting a role for free radicals in the initiation or progression of the lesions (Freedman et al. 1990a, 1991). The earliest molecular markers so far reported in the pathophysiological events are rises in serum substance $P$, calcitonin gene-related peptide (CGRP) and prostaglandin $\mathrm{E}_{2}\left(\mathrm{PGE}_{2}\right)$, which peak on day 5 , accompanied by dramatic increases in histamine and $\gamma$ interferon which peak on day 11 (Weglicki \& Phillips, 1992). During the third week significant circulating levels of soluble inflammatory mediators such as the cytokines interleukin-1 (IL-1), IL-6, and tumour necrosis factor- $\alpha$ (TNF- $\alpha$ ) were also measurable (Weglicki \& Phillips, 1992). However, in all these studies the contribution of cellular mediators of inflammation to the generation of the cardiac lesions has not been investigated. In the present report we show alterations in circulating levels of inflammatory cell subpopulations, and suggest that this leucocytosis is a significant component of the pathophysiological processes observed in Mg-deficiencyinduced cardiomyopathy.

\section{MATERIALS AND METHODS}

\section{Experimental animals}

Male Sprague-Dawley rats, purchased from Hilltop Laboratories (Scottdale, PA, USA) were housed in groups of three to five animals and kept under a $12 \mathrm{~h}$ light-12 h dark cycle with food and deionized water given ad libitum. The experimental protocol involved two treatment regimens, $\mathrm{Mg}$-deficient and $\mathrm{Mg}$-sufficient, with four groups of eight to twelve rats on each regimen. The rats were fed on a standard rodent diet (Teklad, Madison, WI, USA) containing $<1 \mathrm{mmol} \mathrm{Mg}^{2+} / \mathrm{kg}$ for the $\mathrm{Mg}$-deficient group and supplemented with $20 \mathrm{mmol} \mathrm{MgO} / \mathrm{kg}$ for the $\mathrm{Mg}$-sufficient diets. The rodent diet base contained extracted casein which was supplemented with essential vitamins and nutrients to provide optimally controlled experiments. At the end of each week (days 7, 14, 21 and 28) one group of rats from each regimen was killed for investigation of the progress of myocardial injury and assessment of inflammatory response. Animals were anaesthetized with ether, and blood was drawn into Vacutainer tubes containing $2 \mathrm{~g} / 1$ EDTA for cytochemical analysis of total and differential leucocyte counts.

\section{Plasma magnesium measurements}

For the measurement of plasma $\mathrm{Mg}$ levels, blood samples from each animal were mixed with $100 \mathrm{~g} / \mathrm{l}$ sodium citrate $(10: 1, \mathrm{v} / \mathrm{v})$ as anticoagulant. Platelet-poor plasma was separated from whole blood by standard methods (Baenziger \& Majerus, 1974). The plasma $\mathrm{Mg}$ levels were determined by atomic absorption spectroscopy (Varian Instruments, Palo Alto, CA, USA), as previously described (Freedman et al. 1990a, 1991; Weglicki et al. 1993). 


\section{Histopathology}

The severity of myocardial injury was determined by light microscopy. The hearts of the control and $\mathrm{Mg}$-deficient animals were sliced into four segments, and fixed in $10 \%$ formalin. There were eight rats in each of the treatment groups, thus a total of thirty-two heart segments were formalin-fixed for the control group, and also for the Mg-deficient group. Haematoxylin and eosin (H \& E)-stained sections were prepared for morphological and morphometric analyses. An average of thirty sections per heart at different levels, not serial sections, were prepared for the analyses. The morphometric analysis was done using the Bioquant ( $R$ \& $M$ Biometrics, Nashville, TN, USA) image analysis system. The Bioquant, an IBM interactive image analysis system, provided fast direct morphometric measurements from digitized images captured via the automated video counting and microdensitometry accessory program (VCMTE). The myocardial lesions were identified microscopically, and the images viewed on the monitor screen for the automated video counting and quantification. The results are reported as the numerical density (number of lesions $/ \mathrm{cm}^{2}$ of tissue), and the area fraction (lesion area $/ \mathrm{cm}^{2}$ tissue).

\section{Determination of leucocyte subpopulation levels}

Leucocyte levels were determined by flow cytochemistry using the Technicon $\mathrm{H}^{*} 1$ Hematology System (Technicon Instruments Corporation, Tarrytown, NY, USA). The method entailed the initial lysis of erythrocytes $(12 \mu \mathrm{l}$ total volume of blood) using anionic

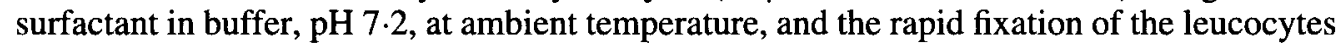
with formaldehyde in phosphate buffer, $\mathrm{pH} 7.2$. The chromogen (4-chloro-1-naphthol) was then added together with the $\mathrm{H}_{2} \mathrm{O}_{2}$ substrate. A dark precipitate developed because of the peroxidase $(E C$ 1.11.1.7) present in the primary granules of the leucocytes. The entire reaction was completed in about $33 \mathrm{~s}$. Since neutrophils, eosinophils, and monocytes contain varying amounts of peroxidase, depending on the cell type, there was variation in the intensity of the staining. Peroxidase is not present in lymphocytes and large unstained cells (LUC). LUC are morphologically large cells of lymphoid origin that are peroxidase negative. The cell suspension from the reaction mixture $(625 \mu$ l effluent) was then passed through a sheathed stream of flow cell in a tungsten-light based cytometer optics channel. The sample flowed in an extremely narrow stream (about $40 \mu \mathrm{m}$ diameter) past a pair of photodetectors so that cells could be analysed one at a time, clustered according to cell type and the clusters analysed by pattern recognition image analysis system and a computerbased algorithm. Basophil number was determined by suspending the blood (12 $\mu \mathrm{l})$ in a phosphate buffer with non-ionic surfactant, $\mathrm{pH} \mathrm{1.9,} \mathrm{to} \mathrm{lyse} \mathrm{erythrocytes} \mathrm{and} \mathrm{platelets,} \mathrm{and}$ to strip the cytoplasm from the leucocytes except basophils (differential lysis). Basophils are extremely resistant and were usually the last to rupture. The reaction time was approximately $57 \mathrm{~s}$ and the assay was done at ambient temperature. The final effluent (500 $\mu \mathrm{l})$ containing the intact basophils and the bare nuclei of other leucocyte types was passed through a sheathed stream of flow cell in a tungsten-light based cytometer optics channel as described earlier (Groner et al. 1986).

\section{Statistical analysis}

The results for the $\mathrm{Mg}$-supplemented and $\mathrm{Mg}$-deficient groups were summarized as mean and standard deviation (SD). The numerical data for the two groups were compared by ANOVA and Duncan's multiple range test. Comparisons between values for events 
observed between-times were assessed by paired $t$ test. Differences among groups were considered significant at $P<0.05$. The numerical data have been summarized and are presented graphically as average values (and SD) (Bourke et al. 1985).

\section{RESULTS}

\section{Plasma magnesium levels}

The Mg-deficient animals had a slower weight gain than the controls fed on the $\mathrm{Mg}$ sufficient diet. The Mg-sufficient groups increased their weights from 139 (SD 4.4) (initial weights) to 297 (SD 6.8) $\mathrm{g}$ at 3 weeks and from 147 (SD 4.4) $\mathrm{g}$ to 366 (SD 8.8) $\mathrm{g}$ at 4 weeks. The Mg-deficient groups increased their weights from 145.9 (SD 3.8) $\mathrm{g}$ to 223 (SD 6.8) $\mathrm{g}$ at 3 weeks and 142 (SD 4.0) $\mathrm{g}$ to 242 (SD 6.0) $\mathrm{g}$ at the end of the fourth week. Paired $t$ test analysis showed that the difference in the body weights was statistically significant $(P<0.01)$. The time-course of the decline in plasma $\mathrm{Mg}$ in the deficient animals is shown in Fig. 1. There was a precipitous fall in the plasma concentration of this divalent cation in the first $5 \mathrm{~d}$, from about $0.75 \mathrm{mM}$ to about $0.3 \mathrm{mM}$ (Fig. 1). During the remaining weeks of the experiment the value remained stable at about $28 \%$ of the control plasma level. The plasma $\mathrm{Mg}$ concentration of control animals on the Mg-sufficient diet did not change during the same period.

\section{Myocardial lesions}

Histological examination of the $\mathrm{H} \&$ E-stained sections of the myocardium showed infiltration of inflammatory cells, suggesting the presence of inflammatory leucocytes. In preliminary studies, the number of infiltrated cells per lesion area, estimated from the histological (H \& E-stained) sections, showed significant increases by the third and fourth

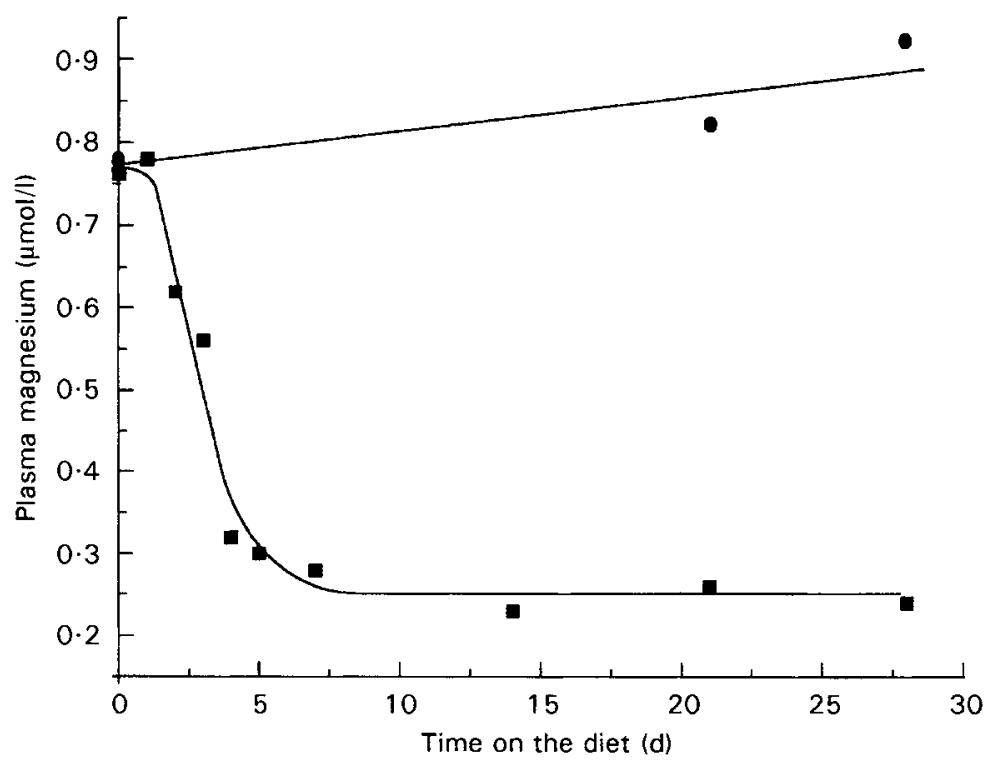

Fig. 1. Plasma magnesium concentration of rats fed on a magnesium-deficient diet $(\mathbf{D})$, containing less than $1 \mathrm{mmol}$ $\mathrm{Mg} / \mathrm{kg}$ for $28 \mathrm{~d}$, and control rats fed on a magnesium-sufficient diet (O). 

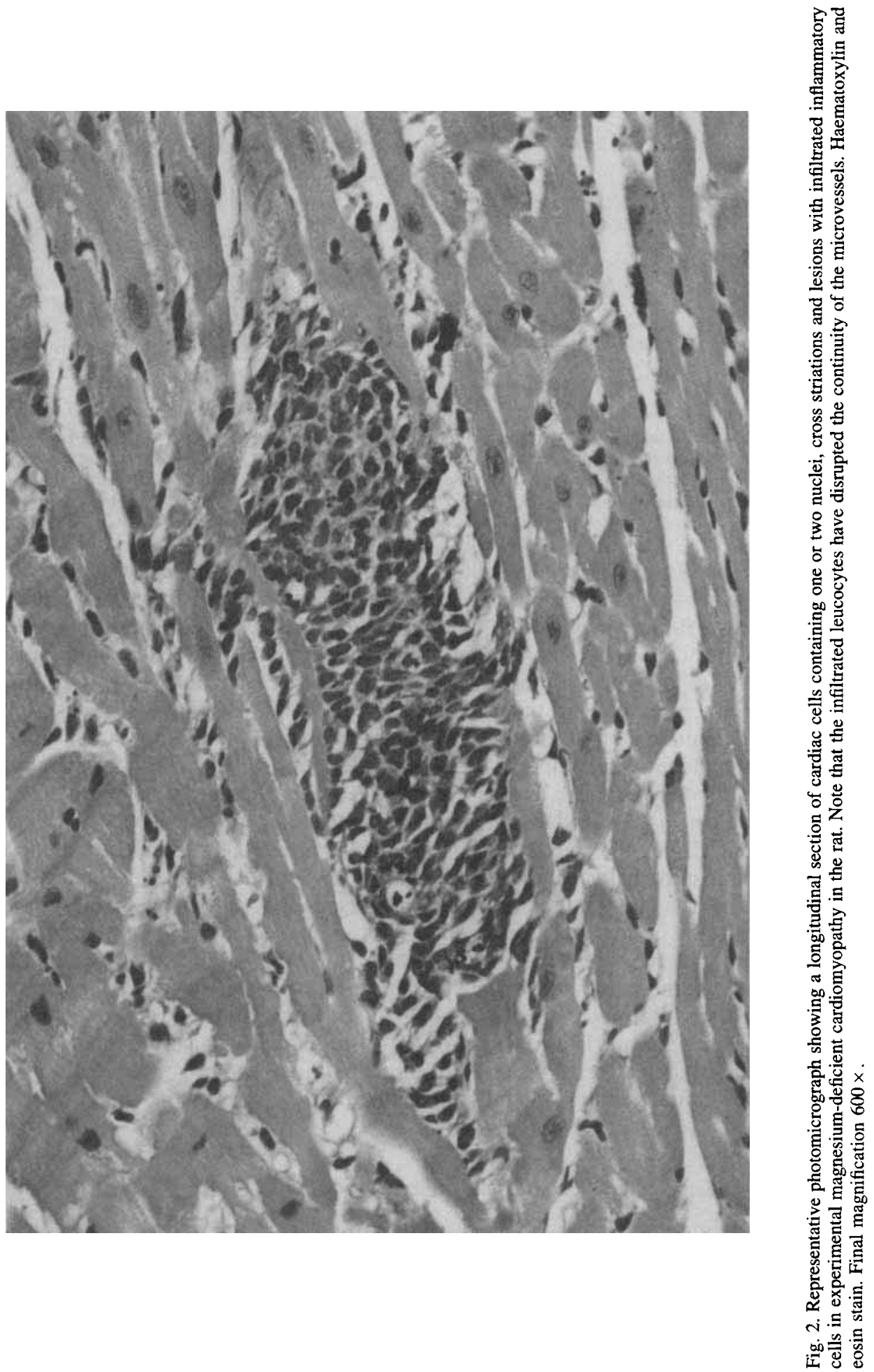


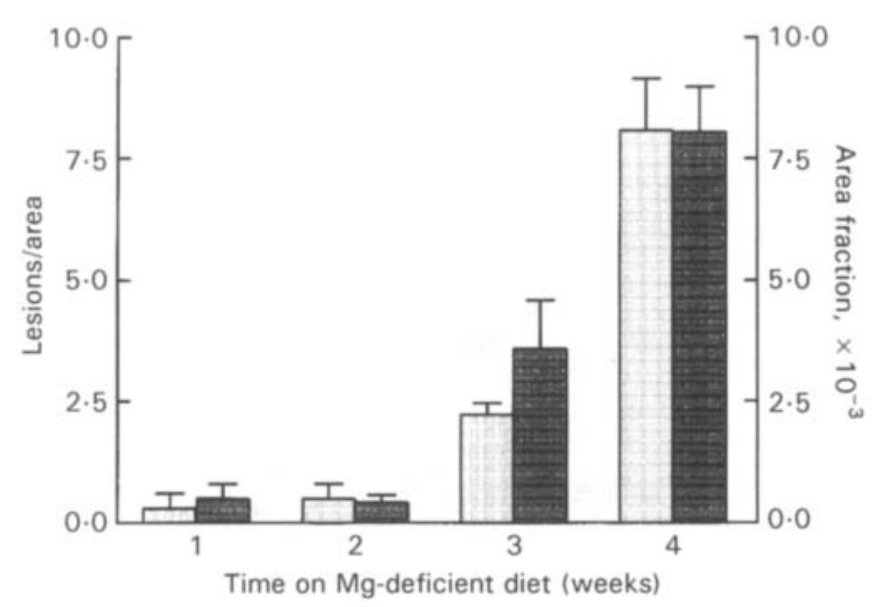

Fig. 3. Myocardial lesions in experimental magnesium-deficient cardiomyopathy in the rat model. Lesions were determined in ventricular sections using the image analysis system described on p. $847(n 8)$. The mean size of the lesions increased significantly between the third and fourth weeks on the magnesium-deficient diet $(P<0.001$, by paired $t$ test) ( $\square$ ) Lesion/area; ( $\square$ ) area fraction.

weeks (results not shown). The myocardium of rats fed on the Mg-deficient diet developed perivascular lesions surrounding microvessels, which increased with time on the diet, and occurred primarily during the third and fourth weeks (Fig. 2). The mean size of the lesions increased significantly between the third and fourth weeks on the Mg-deficient diet (Fig. 3).

Fig. 3 also represents the progression of the focal inflammatory lesions in the myocardium with time. During the first 2 weeks the $\mathrm{H} \&$ E-stained sections showed significant accumulation of infiltrating inflammatory cells. These focal areas of small numbers of inflammatory cells appear to progress to definitive lesions during dietary $\mathrm{Mg}$ restriction. The density of these lesions increased between the third and fourth weeks in this rodent model as an inflammatory infiltrate in the perivascular areas of the microvasculature. Using the paired $t$ test, it was apparent that the mean size of the lesions increased significantly between the third and fourth weeks on the Mg-deficient diet $(P<0.001)$. The lesions per area and the area fraction occupied by the lesions also increased significantly between the third and fourth weeks. Numerous polymorphonuclear leucocytes were present around small blood vessels and many of these were eosinophilic. With increasing duration on the deficient diet, there was monocyte and macrophage accumulation at the perivascular sites, and giant cell formation was also noted, with evidence of calcification at a later time period. By 4 weeks the lesions were more numerous and the myocardial area affected was significantly amplified. A more diffuse infiltration of leucocytes into the interstitium was present at this time.

\section{Circulating inflammatory cells}

The total circulating leucocyte pool increased progressively in the rats on the Mg-deficient diet from the first week to the fourth week. During the $28 \mathrm{~d}$ period, the total circulating leucocytes increased from $8 \times 10^{3} / \mu \mathrm{l}$ on day 7 to $18 \times 10^{3} / \mu \mathrm{l}$ on day 28 . There was no significant change in total circulating leucocytes when the control rats were fed on the standard rodent diet supplemented with $\mathrm{Mg}$ (Fig. 4). However, there were significant differences between the mean values of the circulating leucocytes in the Mg-supplemented and $\mathrm{Mg}$-deficient rats at the first and second weeks, and at the third and fourth weeks 


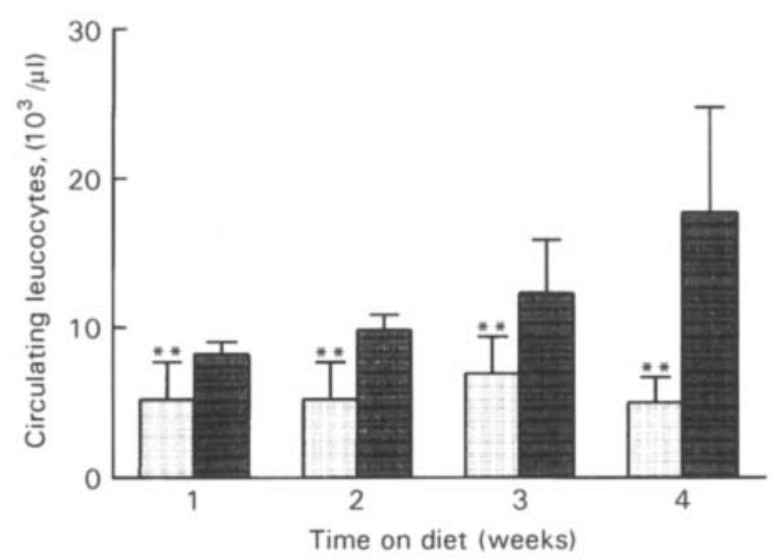

Fig. 4. Alterations in total circulating leucocyte counts in experimental magnesium-deficient cardiomyopathy in the rat fed on a magnesium-deficient diet as a function of time. $(n 10)$. ( $\square$ ), magnesium sufficient; $(\square)$ magnesium deficient, ** Values were significantly different from those for the magnesium-sufficient group at the same time point, $P<0.01$ (paired $t$ test).

$(P<0.01)$. When the proportions of the circulating leucocyte subpopulations were analysed by peroxidase staining reactions in the flow cytometer, the dynamic changes in the specific cell distribution were apparent. Fig. 5 illustrates the dynamic changes in the distribution of leucocyte subpopulations in the $\mathrm{Mg}$-supplemented and $\mathrm{Mg}$-deficient rats during the $28 \mathrm{~d}$ period of the study. It is apparent that elevated circulating levels of neutrophils and lymphocytes contributed to both the acute and chronic phases of the inflammatory responses in the Mg-deficient rats. Monocytes, eosinophils, basophils and LUC, on the other hand, increased significantly in the third and fourth weeks and thus contributed to the chronic phases of the inflammatory response. Quantification of the changes in the leucocyte subpopulations in the third and fourth weeks showed significant elevation in the absolute proportions of these inflammatory cells. During weeks 3 and 4 neutrophils increased 6.4 and 10.4 times respectively; eosinophils increased 2.9 and 10.3 times respectively; basophils increased 1.8 and 7.3 times respectively; total lymphocytes increased 1.6 and 2.7 times respectively; and the absolute proportion of monocytes decreased by $36.4 \%$ in the third week, suggesting an increased sequestration into tissue sites, but increased again by threefold in the fourth week which indicates increased production. However, further differentiation of the dynamic changes in monocyte and lymphocyte subpopulations would require the use of cell type-specific monoclonal antibodies. The LUC increased by $36.6 \%$ and 3.5 times in the third and fourth weeks respectively. LUC which are unstained cells of lymphoid origin and peroxidase negative, may be a facet of accelerated turnover of lymphoid cells. Statistical evaluation using ANOVA of the increase in the mean value of each cell fraction in the $\mathrm{Mg}$-deficient rats between the third and fourth weeks was significant $(P<0.05)$.

\section{DISCUSSION}

Recent experimental evidence suggests that $\mathrm{Mg}$-deficient cardiomyopathy in animal models may be partially mediated by pro-oxidant stress and neurogenic inflammation (Weglicki \& Phillips, 1992; Weglicki et al. 1993). Our observation that there are specific dynamic changes in the circulating subpopulations of leucocytes suggests that $\mathrm{Mg}$ deficiency induces an acute-phase inflammatory response that is followed by a chronic- 


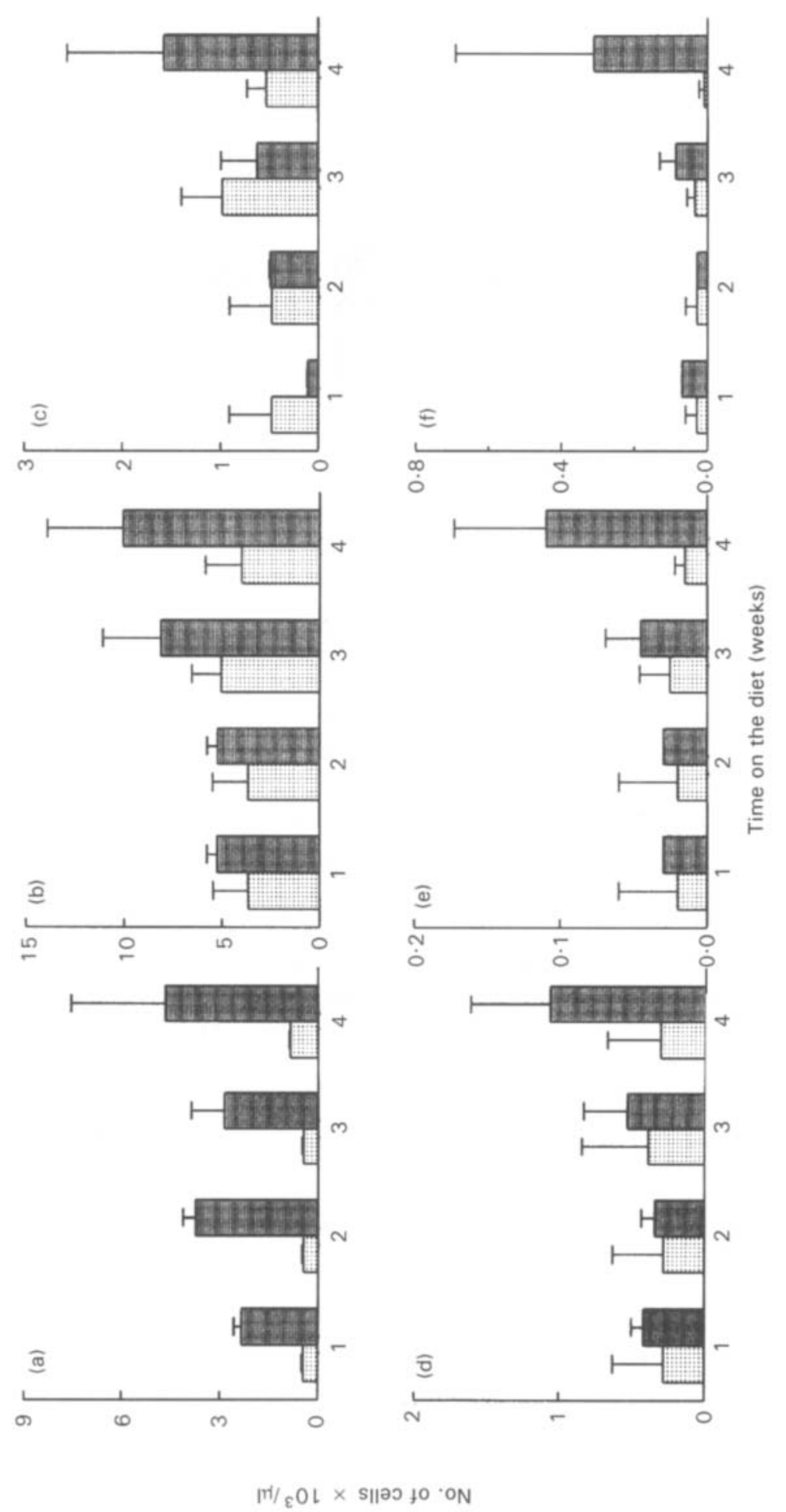

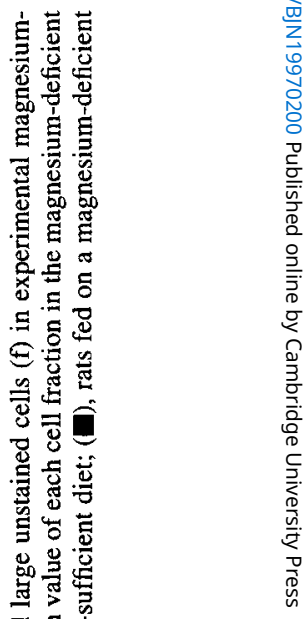


phase inflammation. The major components of an inflammatory process are a rise in circulating polymorphonuclear leucocytes, intravascular stimulation of platelets and endothelial cells, and a cascade of adhesive events involving several adhesion molecules. These pathophysiological events, which are mediated by substance $P$, modulate the vasodilatory response, and the leakage of plasma into the surrounding tissues (Walsh et al. 1995). These factors also influence the adhesion process whereby activated leucocytes adhere to the vascular endothelium, and the infiltration of activated leucocytes into the inflammatory sites. Additionally, inflammatory cells can further exert local and systemic effects by releasing specific bioactive molecules such as histamine and leukotriene $\mathrm{B}_{4}$, (Walsh et al. 1995).

Acute and chronic inflammation represent two poles of a dynamic continuum in which the morphologic features of the inflammatory response frequently overlap the systemic counterpart of local tissue inflammation which is commonly manifested as a 2-3-fold increase in circulating leucocytes, predominantly neutrophilia in the early stages. A 4-fold augmentation in total circulating leucocyte count and in the neutrophil fraction was observed by the fourth week in the Mg-deficient rats (Fig. 5(a)). Neutrophilia may arise due to increased mobilization from the bone-marrow pool or by transference of the cells from the marginated pool along blood vessel walls. This latter storage site, numerically equal to the circulating neutrophil pool, is also briefly recruited by stress-induced release of adrenaline (Dale, 1992). We found prolonged and sustained neutrophilia at 3 and 4 weeks of $\mathrm{Mg}$ deprivation which is similar to the bone mobilization observed in acute inflammatory disorders, for example due to endotoxins or high levels of corticosteroids (Dale, 1992; Warren et al. 1992; Olivares et al. 1993). Eosinophilia, which occurred dramatically by week 4 in these studies, is usually a response to chemotactic substances produced by mast cells, including histamine, and eosinophils accumulate preferentially in sites of mast cell degranulation. In this rodent model of $\mathrm{Mg}$-deficiency, the number and size of the myocardial lesions increased during the 4-week period in a manner that closely paralleled the enhanced peripheral leucocytosis (Figs. 3 and 4). The sequence of events appears to be initiated by an early neurogenic inflammatory process through the secretion of substance $\mathrm{P}$, and CGRP which are triggered by plasma and/or tissue $\mathrm{Mg}$ depletion (Weglicki \& Phillips, 1992; Phillips \& Weglicki, 1994). Furthermore, Weglicki \& Phillips (1992) reported that sequential analysis of the plasma levels of substance P, PGE $2 \gamma-$ interferon, cytokines (IL-1, IL-6, and TNF- $\alpha$ ), and histamine revealed that substance P, CGRP and $\mathrm{PGE}_{2}$ peaked by day 5 , whereas histamine and $\gamma$-interferon peaked on day 12 , followed by a major elevation of the cytokines on day 21 . These chronological alterations in the inflammatory molecular mediators mirror the changes in the circulating leucocyte subpopulations observed in the present study. The extent of neurogenic inflammatory modulation in tissues depends on the degree and type (transmitter pattern and chemical coding) of afferent innervation by the associated fibres. Nerve endings that contain substance $P$ and CGRP innervate blood vessels throughout the body, forming para- and perivascular networks which also innervate vascular smooth muscle (Hokfelt, 1991; Donnerer \& Amann, 1993). In our model of neurogenic inflammation induced by dietary $\mathrm{Mg}$ restriction, a significant rise in both the neutrophil and lymphocyte count occurred within 1 week, and was followed by cardiomyopathic lesions that were infiltrated with peroxidase-positive polymorphonuclear leucocytes (Bruce et al. 1995). Both of these variables were considerably amplified in weeks 3 and 4 with a continuous increment in circulating lymphocytes and macrophages and their deposition within the focal myocardial lesions. Thus, an acute inflammatory response proceeding to a chronic inflammatory phase by week 4 was induced by the $\mathrm{Mg}$-deficient diet. This form of neurogenic inflammation 
was observed in the absence of any demonstrable viral or microbial infection as the aetiological agent (results not shown). The cellular sources of the reported elevation of plasma concentrations of histamine, cytokines and other bioactive molecules are at present unknown (Weglicki \& Phillips, 1992). In summary, we suggest that the recruitment and stimulation of inflammatory cells early during the acute phase, and later during the chronic phase of $\mathrm{Mg}$ deficient neurogenic inflammation may possibly be mediated by elevations in cytokines, chemotactic and vasoactive factors which have been observed in this deficiency model (Weglicki \& Phillips, 1992). Further studies are needed to elucidate the mechanisms whereby polymorphonuclear leucocyte recruitment, stimulation and possible adhesion to the vascular endothelium is mediated and extravasation of plasma and blood cells into the myocardial tissue ensues.

We appreciate the technical assistance of Patricia Boehme and Sandra Pierre. We thank Drs T. M. Phillips and B. F. Dickens of the Department of Medicine, The George Washington University Medical Center for critically reviewing the manuscript and providing useful comments. We also thank Dr B. F. Dickens for assisting us with computer graphics. This research was supported by grants no. RO1-HL49232 and no. RO1-HL36418 from the National Heart, Lung and Blood Institute, National Institutes of Health, USPHS, Bethesda, MD, USA.

\section{REFERENCES}

Aikawa, J. K. (1981). Magnesium: Its Biologic Significance. Boca Raton, FL: CRC Press.

Altura, B. M. (1986). Magnesium, stress, and the cardiovascular system. Magnesium 5, 103-220.

Baenziger, N. L. \& Majerus, P.W. (1974). Isolation of human platelets and platelet surface membranes. Methods in Enzymology 31, 149-155.

Battifora, H. (1973). Effect of magnesium deficiency on blood cells: clinical and experimental data. In First International Symposium on Magnesium Deficiency in Human Pathology, pp. 501-515, [J. Durlach, editor]. Paris: 'Société Générale de l'Eau Minérale, Vittel' Press.

Bourke, G. J., Daly, L. E. \& McGilvaray, J. (1985). Interpretation and Uses of Medical Statistics, 3rd ed. London: Blackwell Scientific Publications.

Bruce A., Bruce, V., Kurantsin-Mills, J., Cassidy, M. M., Stafford, R. E. \& Weglicki, W. B. (1995). Myocardial myeloperoxidase activity and cardiomyopathic injury during magnesium deficiency. FASEB Journal 9 , A708.

Dale, D. C. (1992). Neutrophilia. In Hematology, 4th ed., pp. 816-820 [W. J. Williams, E. Beutler, A. J. Erslev and M. A. Lichtman, editors]. New York, NY: McGraw-Hill Publishing Co.

Donnerer, J. \& Amann, R. (1993). The inhibition of neurogenic inflammation. General Pharmacology 24, 519529.

Freedman, A. M., Atrakchi, A. H., Cassidy, M. M., Muesing, R. A. \& Weglicki, W. B. (1990a). Magnesium deficiency-induced cardiomyopathy: protection by vitamin E. Biochemical and Biophysical Research Communications 170, 1102-1106.

Freedman, A. M., Cassidy, M. M., Muesing, R. A. \& Weglicki, W. B. (1991). Captopril protects against myocardial injury induced by magnesium deficiency. Hypertension (Dallas) 18, 142-147.

Freedman, A. M., Mak, I. T., Cassidy, M. M. \& Weglicki, W. B. (1990b). Magnesium deficient red blood cells exhibit an enhanced sensitivity to oxidative stress. Free Radical Biology and Medicine 9, 119.

Groner, W., Boyett, J., Johnson, A. \& Scantlebury, M. (1986). Variability of erythrocyte size and hemoglobin content observed in man and four selected mammals. Blood Cells 12, 65-80.

Hokfelt, T. (1991). Neuropeptides in perspective: the last ten years. Neuron 7, 867-879.

Mills, B. J., Linderman, R. D. \& Lang, C. A. (1986). Magnesium deficiency inhibits biosynthesis of blood glutathione and tumor growth in the rat (42260). Proceedings of the Society for Experimental Biology and Medicine 181, 326-332.

Olivares, R., Ducimetière, P. \& Claude, J. R. (1993). Monocyte count: a risk factor for coronary heart disease? American Journal of Epidemiology 137, 49-53.

Phillips, T. M. \& Weglicki, W. B. (1994). Elevated tumor necrosis factor (TNF $\alpha$ ) levels in the myocardium of $\mathrm{Mg}$-deficient (Mg-Def) rats: inhibition by substance $\mathrm{P}(\mathrm{SP})$ receptor blockade. FASEB Journal, 8, A663.

Rishi, M., Ahman, A., Makheja, A., Karcher, D. \& Bloom, S. (1990). Effect of reduced dietary magnesium on platelet production and function in hamsters. Laboratory Investigation 63, 717-721. 
Seelig, M. S. (1989). Cardiovascular consequences of magnesium deficiency and loss. American Journal of Cardiology 63, 4G-21G.

Seelig, M. S. \& Heggtveit, H. A. (1974). Magnesium interrelationships in ischemic heart disease: a review. American Journal of Clinical Nutrition 27, 59-79.

Tongyai, S., Rayssiguier, Y., Motta, C., Gueux, E., Maurois, P. \& Heaton, F. W. (1989). Mechanism of increased erythrocyte membrane fluidity during magnesium deficiency in weanling rats. American Journal of Physiology 257, C270-C276.

Walsh, D. T., Weg, V. B., Williams, T. J. \& Nourshargh, S. (1995). Substance P-induced inflammatory responses in guinea pig skin: the effect of specific $\mathrm{NK}_{1}$ receptor antagonists and the role of endogenous mediators. British Journal of Pharmacology, 114, 1343-1350.

Warren J. S., Ward, P. A. \& Johnson, K. J. (1992). The inflammatory response. In Hematology, 4th ed., pp. 6370 [W. J. Williams, E. Beutler, A. J. Erslev and M. A. Lichtman, editors]. New York, NY: McGraw-Hill Publishing Co.

Weglicki, W. B. \& Phillips, T. M. (1992). Pathobiology of magnesium deficiency: a cytokine/neurogenic inflammation hypothesis. American Journal of Physiology 263, R734-R737.

Weglicki, W. B., Stafford R. E., Freedman A. M., Cassidy, M. M. \& Phillips, T. M. (1993). Modulation of cytokines and myocardial lesions by vitamin $\mathrm{E}$ and chloroquine in a $\mathrm{Mg}$-deficient rat model. American Journal of Physiology 264, C723-C736. 